\begin{tabular}{|c|c|}
\hline Title & $\begin{array}{l}\text { In situ, real-time monitoring of electrode surfaces by scanning tunneling microscopy. III. Surface structure of Pt and Pd } \\
\text { electrodes }\end{array}$ \\
\hline Author(s) & U osaki, Kohei; Kita, Hideaki \\
\hline Citation & $\begin{array}{l}\text { Journal of V acuum Science \& Technology A : V acuum, Surfaces, and Films, 8(1), 520-524 } \\
\text { https://doi.org/10.1116/1.576379 }\end{array}$ \\
\hline Issue Date & 1990-01 \\
\hline Doc URL & http:/hdl .handle.net/2115/5702 \\
\hline Rights & Copyright $\odot 1990$ A merican Institute of Physics \\
\hline Type & article \\
\hline File Information & JV S\&TA-V SF8 1.pdf \\
\hline
\end{tabular}

Instructions for use 


\title{
In situ, real-time monitoring of electrode surfaces by scanning tunneling microscopy. III. Surface structure of Pt and Pd electrodes
}

\author{
Kohei Uosaki and Hideaki Kita \\ Department of Chemistry, Faculty of Science, Hokkaido University, Sapporo 060, Japan
}

(Received 10 July 1989; accepted 23 August 1989)

\begin{abstract}
$\mathrm{Pt}$ and Pd electrodes were monitored by STM in situ in real time. In the case of Cu deposition on $\mathrm{Pd}$, small domains of $\mathrm{Cu}$ were first formed and they gradually merged to form terraces. The surface finally became relatively smooth. Surface structure change of Pt electrode during oxide formation/reduction was also investigated. Growth of parallel ridge and domelike structures was observed.
\end{abstract}

\section{INTRODUCTION}

It is well recognized that the structure of electrode surfaces has a significant effect on the reactivity of the electrode. Not only the real surface area for the reaction is increased by the roughness of the electrode but also the microstructure of the surface is strongly correlated with the number and the distribution of the active sites. Moreover, the surface structure of the electrode often changes during the electrochemical reaction caused by adsorption/desorption of metal atoms or even by formation/reduction of oxide layer.

To understand the effect of surface structure on the reactivity of the electrode, it is essential to monitor the surface structure of the electrode with high resolution (atomic to $\mu \mathrm{m}$ scale). The presence of an electrolyte solution in electrochemical systems inhibits the extensive use of surface analysis tools such LEED, most of which can be used only under ultrahigh vacuum (UHV) conditions. Furthermore, most of the techniques have relatively low resolution both laterally and vertically. Scanning tunneling microscope (STM) which has been developed significantly within last few years is most suited for this purpose. ${ }^{1}$ A real space image of conductive surface can be obtained relatively easily with very high resolution in various media including electrolyte solutions. To apply STM to electrochemical situation, however, special care must be taken. Apart from the sample and the tip, which are needed for usual STM measurements in vacuum or in air, it is necessary to add extra two electrodes to the system. A reference electrode is required as a reference potential point and a counterelectrode to carry electrochemical current which flows at the sample (working electrode). In the electrochemical STM measurement, not only the bias between the sample and the tip but also the potential of the sample with respect to the reference electrode should be controlled. In fact, the potential of the sample and the tip are set independently with respect to the reference electrode. Various groups have reported the construction of STM systems for electrochemical study. ${ }^{2-10}$ We have also constructed an STM system for electrochemical application based on a commercially available STM with a homebuilt potentiostat and applied the system for the study of $\mathrm{Cu}$ deposition on $\mathrm{Pt} .{ }^{11}$ With our system, we can follow the dynamics of surface

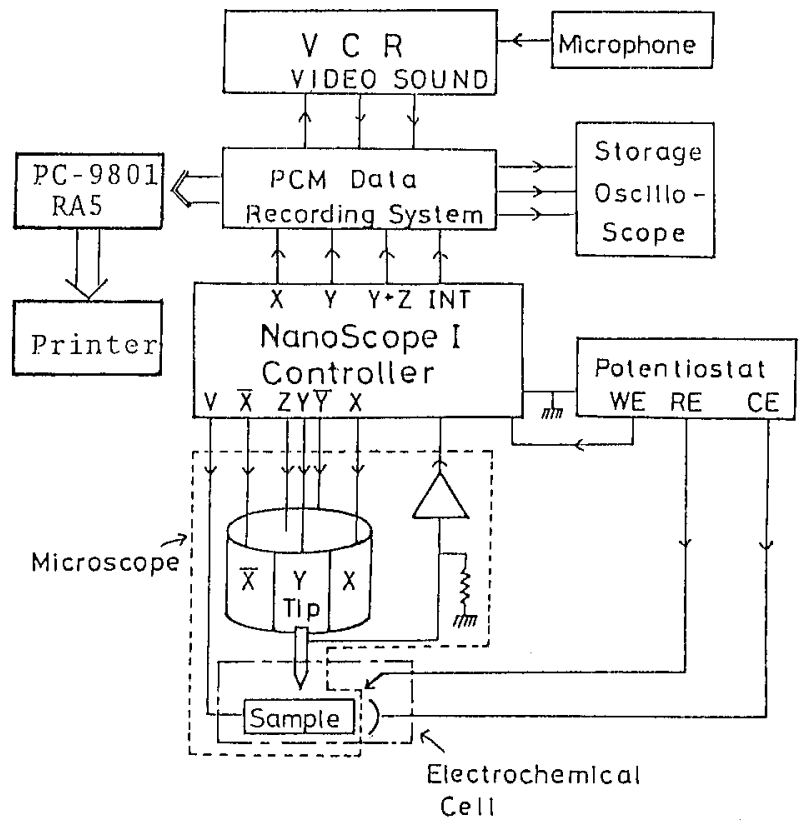

(a)

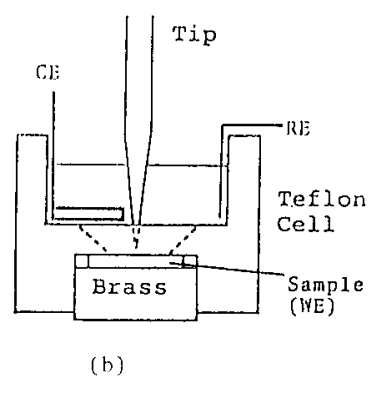

FIG. 1. Block diagram of the present STM system. 
structure change during electrochemical reactions.

In this article, we continued further the study of in situ, real time monitoring of electrode surfaces. The systems investigated in this study are $\mathrm{Cu}$ deposition on $\mathrm{Pd}$ electrode and surface structure change of $\mathrm{Pt}$ during the formation/ reduction of oxide layer.

\section{STM SYSTEM FOR ELECTROCHEMICAL STUDY}

A block diagram of the present STM system is shown in Fig. 1 (a). A STM used in this study was a NanoScope I of Digital Instruments (CA, U.S.A.). A homebuilt potentiostat was added to the system to control the potential of the tip and a sample with respect to a reference electrode and carry out electrochemical reactions. A potential control circuitry of the system is essentially of a well known four electrode potentiostat (bipotentiostat) commonly used for a rotating ring disk electrode and was presented before. " $\mathrm{A}$ Pt wire and a $\mathrm{Pt}$ foil were used as a reference electrode (RE) and a counter electrode (CE), respectively. The working electrode (WE) output of the potentiostat is connected to the external bias input of the NanoScope I which is connected to the base of the microscope on which an electrochemical cell [Fig. 1(b)] is placed. The ground of the potentiostat and that of the control unit of NanoScope I are connected. A PCM data recording system (NF Electronics, RP-880) with a VCR is employed for continuous data recording. More
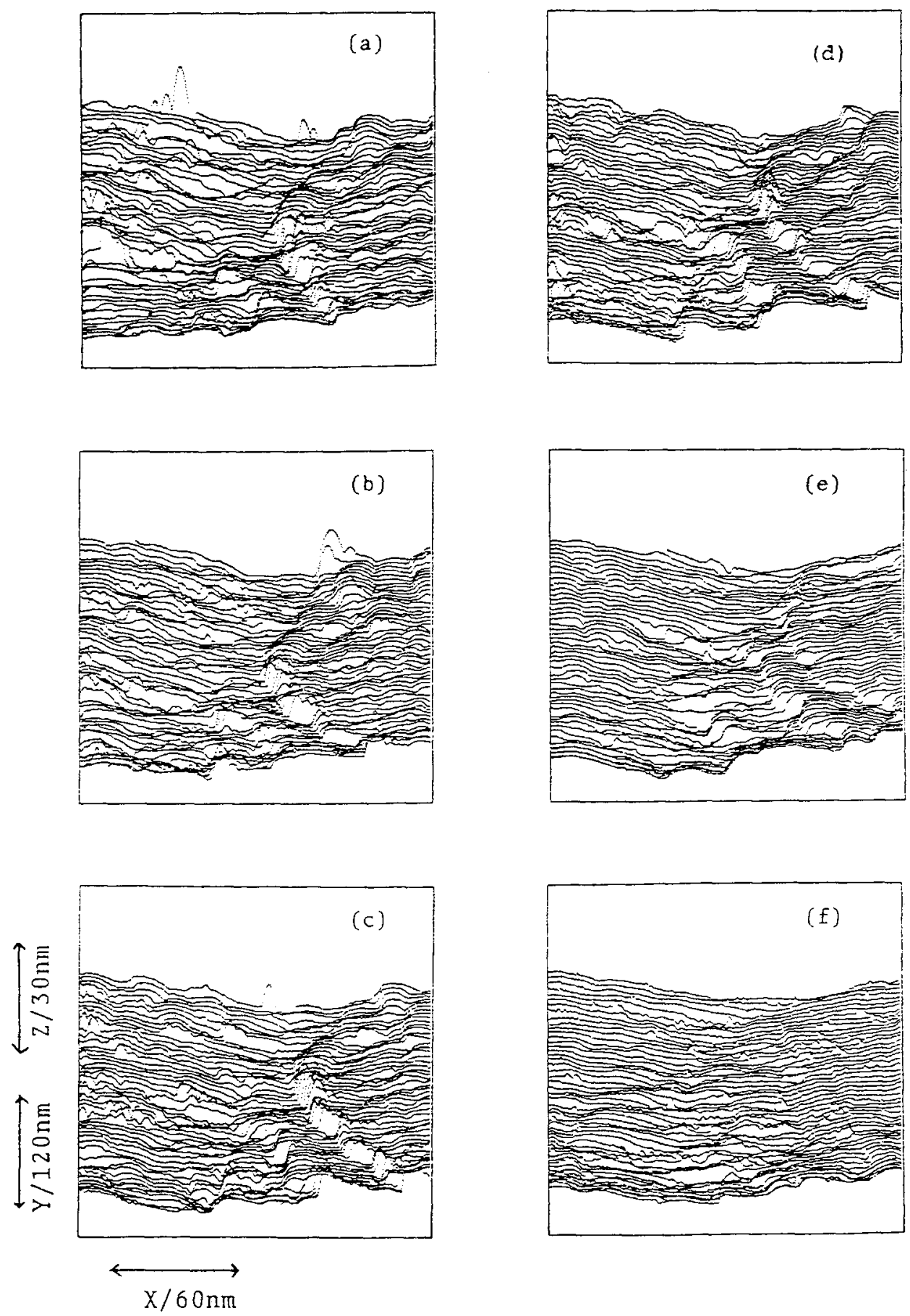

FIG. 2. STM images of Pd electrode surface obtained during $\mathrm{Cu}$ deposition in 2 $\mathrm{mM} \mathrm{HClO}_{4}+5 \mathrm{mM} \mathrm{CuSO}_{4}$. Electrode potential of Pd: $0 \mathrm{~V}$ vs Pt. Current: -10 $\mu \mathrm{A} / \mathrm{cm}^{-2}$. Tip potential: $+700 \mathrm{mV}$ vs Pt. (a) $8 \mathrm{~s}$, (b) $30 \mathrm{~s}$, (c) $45 \mathrm{~s}$, (d) $83 \mathrm{~s}$, (e) $98 \mathrm{~s}$, and (f) $118 \mathrm{~s}$ after the potential was applied. 
than $1 \mathrm{G}$ byte of information can be stored on a $2 \mathrm{~h}$ tape (cf. an ordinary $2 \mathrm{HD}$ floppy disk has storing capacity of $1 \mathrm{M}$ byte). Thus, by using this system, vast amounts of information can be stored very economically. This system has a digital output for further data processing by a computer (NEC, 32 bit, PC9801 RA5 with 40 M byte hard disk system). Turbo $\mathrm{C}$ was used for the main program but the data transfer routine was written in machine code. Played-back STM images can be monitored by using a storage oscilloscope and obtained as hard copy of CRT images of the computer.

Tunneling tips employed are $\operatorname{Pt}(90 \%)-\operatorname{Ir}(10 \%)$ of Longreach Scientific Resources (Maine, U.S.A.), $(\phi=0.25$ $\mathrm{mm}$ ) coated with soft glass or epoxy resin except at the very tip $(\sim 5 \mu \mathrm{m})$.

\section{RESULTS AND DISCUSSION}

\section{A. $\mathrm{Cu}$ deposition on $\mathbf{P d}$}

Metal deposition is one of the most important electrochemical processes both fundamentally and practically. There have been many publications concerning how deposition proceeds and how the electrochemical conditions affect the structure of the deposits. Thus, it is natural to try to investigate the electrochemical metal deposition by STM.
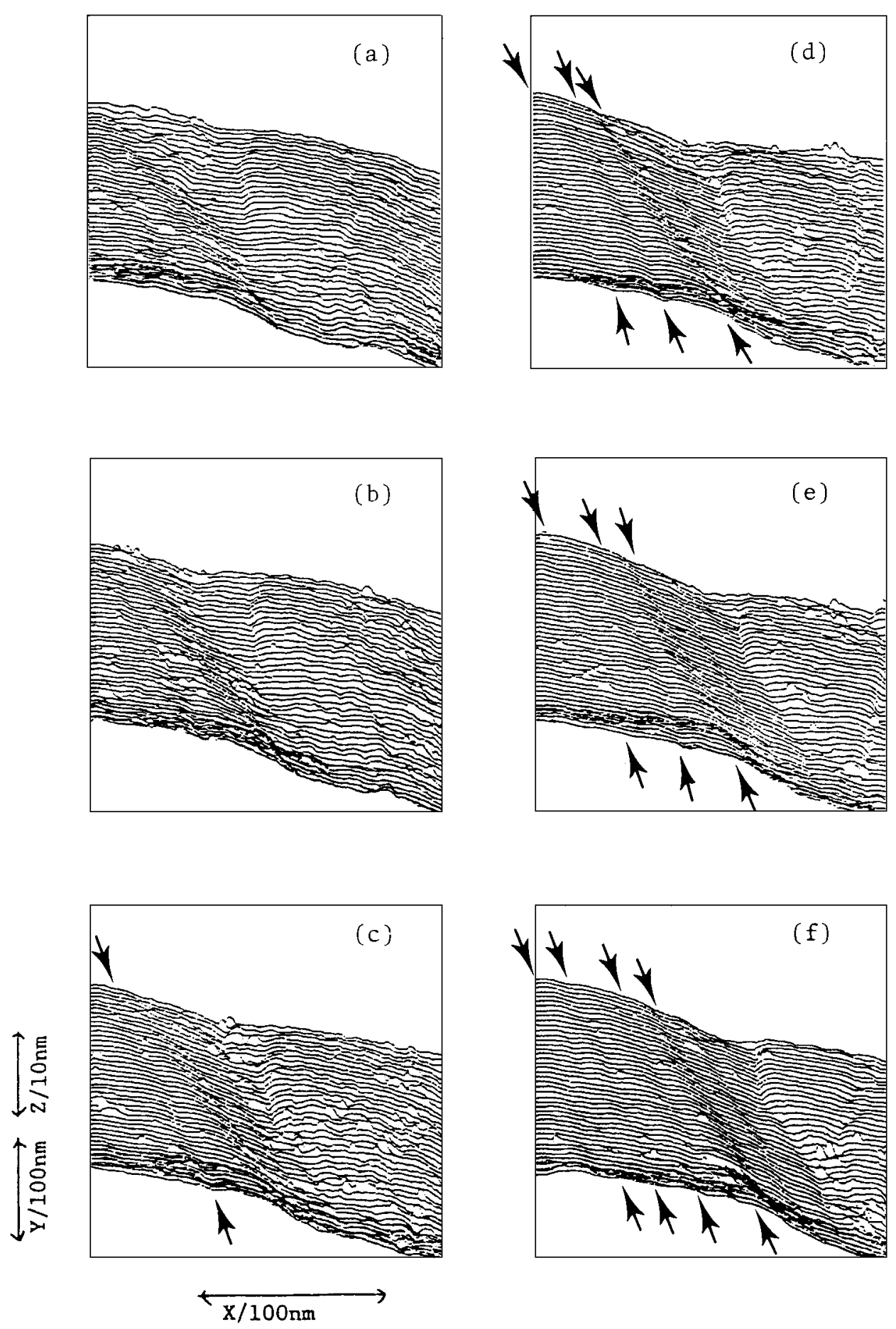

FIG. 3. STM images of Pt surface (a) 45 $\mathrm{s}$, (b) $2 \min 26 \mathrm{~s}$, (c) $2 \min 56 \mathrm{~s}$, (d) 4 min $56 \mathrm{~s}$, (e) $11 \mathrm{~min} 15 \mathrm{~s}$, and (f) $15 \mathrm{~min}$ $19 \mathrm{~s}$ after potential was pulsed from +950 to $-350 \mathrm{mV}$ in $2 \mathrm{mM} \mathrm{HClO}_{4}$. 
We have successfully followed Cu deposition on Pt by STM as mentioned before. ${ }^{11}$ Recently, several electrochemical studies on underpotential deposition (UPD) of $\mathrm{Cu}$ on $\mathrm{Pd}$ were published. ${ }^{12,13}$ Before studying UPD of $\mathrm{Cu}$ on $\mathrm{Pd}$, we investigated the bulk deposition of $\mathrm{Cu}$ on Pd by STM. Figure 2 shows the real time STM images of Pd during $\mathrm{Cu}$ deposition in $2 \mathrm{mM} \mathrm{HClO}_{4}+5 \mathrm{mM} \mathrm{CuSO}_{4}$ at $0 \mathrm{~V}$ vs Pt obtained in situ. To avoid the $\mathrm{Cu}$ deposition on the tip, the tip potential was kept at $+700 \mathrm{mV}$ vs Pt. At the initial stage [Figs.
2 (a) and 2(b)], rather noisy images were obtained and small domains, possibly of $\mathrm{Cu}$, were observed. The domains grew laterally with time and merged to form terraces as shown in Figs. 2(c) and 2(d). Further deposition seemed to occur preferentially at step portion [Fig. 2(e)] and the surface finally became relatively smooth [Fig. 2(f)]. STM images became stable as deposition proceeded. We can speculate that the noisy portion is the place where preferential deposition is taking place.
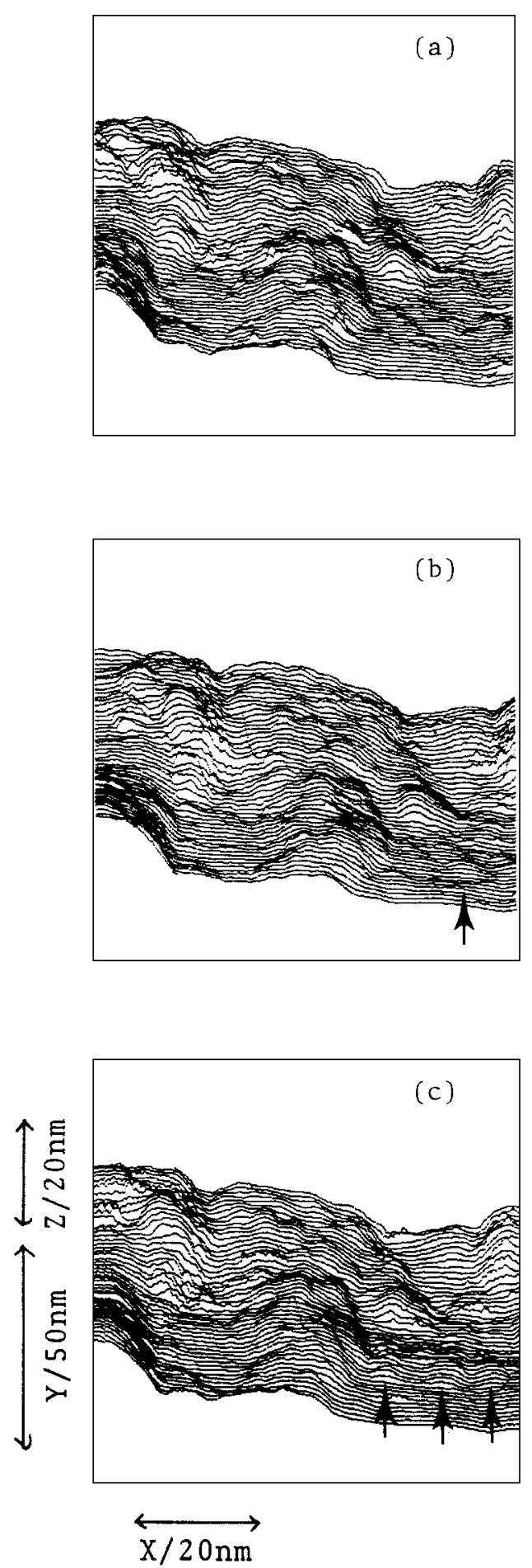
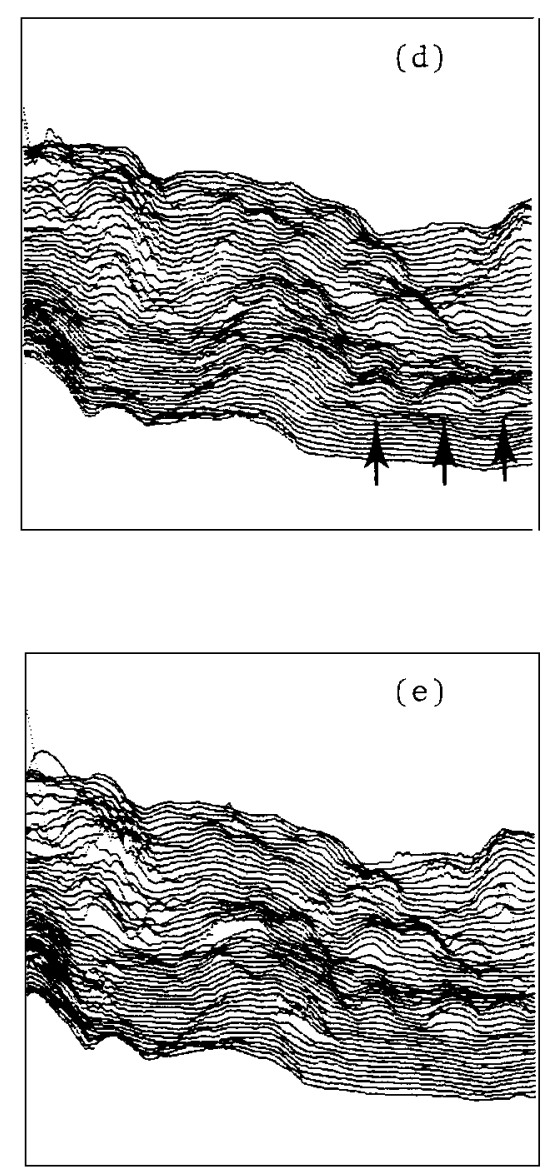

Fig. 4. STM images of Pt surface (a) 8 $\min 21 \mathrm{~s}$, (b) $8 \min 50 \mathrm{~s}$, (c) $9 \min 10 \mathrm{~s}$, (d) $9 \min 20 \mathrm{~s}$, (e) $9 \min 30 \mathrm{~s}$, and (f) 9 $\min 40 \mathrm{~s}$ after potential was pulsed from $+1.5 \mathrm{~V}$ vs Pt to $-1.1 \mathrm{~V}$ vs Pt.

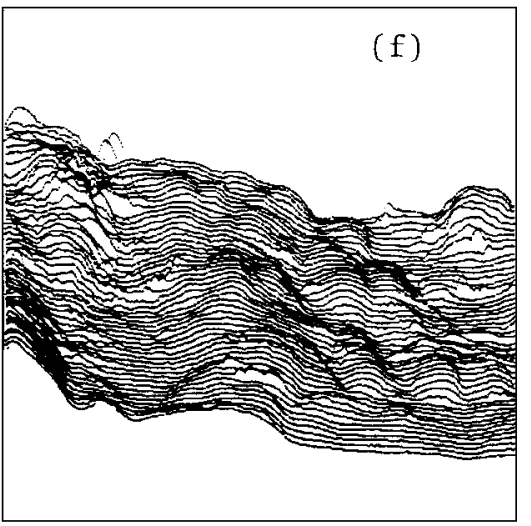




\section{B. Structure change of Pt surface by formation/ reduction of oxide}

Surface structure change of noble metal electrodes due to potential cycles have been pointed out and several STM studies have been reported. ${ }^{14-16}$ Although in situ STM investigation of this process has been carried out, ${ }^{16}$ no report of in situ, real time monitoring of the surface structure change by STM is available. Figure 3 shows STM images of polycrystalline Pt surface in $2 \mathrm{mM} \mathrm{HClO}_{4}$ solution when the potential was first pulsed to $+950 \mathrm{mV}$ vs $\mathrm{Pt}$ at which $\mathrm{Pt}$ oxide layer was formed and then pulsed to $-350 \mathrm{mV}$ vs Pt to reduce the oxide layer. The potential of the $P t$ electrode and the tip were kept at $-350 \mathrm{mV}$ vs Pt and $+550 \mathrm{mV}$ vs Pt, respectively, during STM imaging. There seemed to exist two large domains which merge at the middle of the image. The domains on the left-hand side had a steep slope and the one on the right-hand portion was relatively flat [Fig. 3(a) ]. At the beginning,the left hand-portion had a featureless surface and there was a terrace surrounded by sharp steps in the flat area of the right-hand portion. As time passed, parallel ridge structures with steps of mono to several atomic heights became visible at the left-hand portion as pointed out by arrows [Figs. 3(c)-3(f)]. Separation of these terraces are $\sim 20 \mathrm{~nm}$. These results are quite similar to those of Itaya $e t$ al. obtained in $\mathrm{H}_{2} \mathrm{SO}_{4}$ solution, ${ }^{16}$ although they did not monitor the surface continuously. We must stress that the STM images reported here were obtained in situ, in real time, i.e., the tip was never retracted. It should be also noted here that the resolution of the present system is quite high. Figure 4 shows STM images of $\mathrm{Pt}$ taken in a separate experiment but in the same solution. The potential of the Pt electrode was first kept at $+1.5 \mathrm{~V}$ vs Pt. Even oxygen gas bubble evolving from the Pt surface was clearly observed at this potential. The potential was then pulsed to $-1.5 \mathrm{~V}$ vs $\mathrm{Pt}$ at which reduction of oxide layer should occur. All the STM images shown in Fig. 4 were obtained at this potential. No clear change was observed within this region during the first $8 \mathrm{~min}$ after the potential pulse. However, as shown in Fig. 4(b), a small cluster started to grow after $8 \mathrm{~min} 50 \mathrm{~s}$ at the flat portion seen in the front-right part of the image as indicated by an arrow. Once this change had started, relatively quick structure change was observed in this region. The cluster became three parallel rows within $20 \mathrm{~s}$ [ Fig. 4(c)-4(e)] and finally a domelike structure became dominant in the flat region [Fig. 4(f) ]. Of course, this result does not mean that nothing happened at the surface during the first $8 \mathrm{~min}$. Some change might take place at other part of the surface where STM images has not been recorded. These STM images (Figs 3 and Fig. 4) show that the surface structure change in the electrochemical situation occurs with quite a long time constant. It is interesting to note that Vazquez et al. examined Pt surface ex situ by STM after potential cycles and found both parallel ridge and domelike structures. ${ }^{15} \mathrm{Al}$ though it is not yet clear why these structures developed but it is demonstrated in this paper that in situ, real time monitoring electrode surface certainly provides useful information how these structures grow and with more investigations we expect to find eventually the answer why a certain structure grows at a given point.

\section{ACKNOWLEDGMENTS}

This work was partially supported by Kurata Scholarship of Kokusan Gizyutu Shinkoukai and International Scientific Research Program (Joint Research 01044005) of Ministry of Education, Science and Culture, Japan. Mr. M. Fukuda is acknowledged for the development of computer software.

'P. D. Hansma and J. Tersoff, J. Appl. Phys. 61, R1 (1987).

${ }^{2}$ R. Sonnenfeld and B. C. Schardt, Appl. Phys. Lett. 49, 1172 (1986).

${ }^{3}$ B. Drake, R. Sonnenfeld, J. Schneir, and P. K. Hansma, Surf. Sci. 181, 92 (1987).

${ }^{4}$ H.-Y. Liu, F.-R. F. Fan, C. W. Lin, and A. J. Bard, J. Am. Chem. Soc. 108, 3838 (1986).

${ }^{5}$ O. Lev, F.-R. Fan, and A. J. Bard, J. Electrochem. Soc. 135, 783 (1988).

${ }^{6} \mathrm{~K}$. Itaya and S. Sugawara, Chem. Lett. 1987, 1927.

${ }^{7}$ K. Itaya and E. Tomita, Surf. Sci. 201, L507 (1988)

${ }^{8}$ P. Lustenberger, H. Rohrer, R. Christroph, and H. Siegenthaler, J. Electroanal. Chem. 243, 225 (1988).

${ }^{9} \mathbf{J}$. Wiechers, T. Twomey, D. M. Kolb, and R. J. Behm, J. Electroanal. Chem. 248, 451 (1988).

${ }^{10}$ M. H. J. Hottenhuis, M. A. H. Mickers, J. W. Gerritsen, and J. P. van der Eerden, Surf. Sci. 206, 259 (1988).

"K. Uosaki and H. Kita, J. Electroanal. Chem. 259, 301 (1989)

${ }^{12}$ T. Chierchie and C. Mayer, Electrochim. Acta 33, 341 (1988).

${ }^{13}$ T. Solomun, J. Electroanal. Chem. 261, 229 (1989).

${ }^{14}$ J. Gomez, L. Vazquez, A. M. Baro, N. Garcia, C. L. Perdriel, W. E. Triaca, and A. J. Arvia, Nature 323, 612 (1986).

${ }^{15}$ L. Vazquez, J. Gomez, A. M. Baro, N. Garcia, M. L. Marcos, J. Gonzalez Valesco, J. M. Vara, A. J. Arvia, J. Presa, A. Garcia, and M. Aguilar, J. Am. Chem. Soc. 109, 1730 (1987)

${ }^{16}$ K. Itaya, K. Higaki, and S. Sugawara, Chem. Lett. 1988, 421. 